\title{
Mid-portion Achilles tendinopathy: why painful? An evidence-based philosophy
}

\author{
Maayke N. van Sterkenburg • C. Niek van Dijk
}

Received: 17 January 2011/ Accepted: 28 April 2011/Published online: 13 May 2011

(C) The Author(s) 2011. This article is published with open access at Springerlink.com

\begin{abstract}
Chronic mid-portion Achilles tendinopathy is generally difficult to treat as the background to the pain mechanisms has not yet been clarified. A wide range of conservative and surgical treatment options are available. Most address intratendinous degenerative changes when present, as it is believed that these changes are responsible for the symptoms. Since up to $34 \%$ of asymptomatic tendons show histopathological changes, we believe that the tendon proper is not the cause of pain in the majority of patients. Chronic painful tendons show the ingrowth of sensory and sympathetic nerves from the paratenon with release of nociceptive substances. Denervating the Achilles tendon by release of the paratenon is sufficient to cause pain relief in the majority of patients. This type of treatment has the additional advantage that it is associated with a shorter recovery time when compared with treatment options that address the tendon itself. An evidence-based philosophy on the cause of pain in chronic mid-portion Achilles tendinopathy is presented.

Level of evidence $\mathrm{V}$.
\end{abstract}

Keywords Achilles · Mid-portion · Painful · Cause of pain - Tendon

\section{Introduction}

Chronic Achilles tendon pathology is one of the most frequent injuries in sports involving running and jumping. In elite long-distance runners, there is a lifetime risk of

M. N. van Sterkenburg $(\bowtie) \cdot$ C. N. van Dijk

Department of Orthopaedic Surgery, Academic Medical Center, P.O. Box 22700, 1100 DE Amsterdam, The Netherlands

e-mail: m.n.vansterkenburg@amc.uva.nl
52\% for sustaining an Achilles tendon injury [39]. Thirty per cent of patients have a sedentary lifestyle [7].

Chronic mid-portion Achilles tendinopathy [78] is characterised by impaired performance due to Achilles tendon pain and swelling located typically at $2-7 \mathrm{~cm}$ from the insertion onto the calcaneus [48]. The source of pain and the background to the pain mechanisms associated with mid-portion Achilles tendinopathy have not yet been clarified [49]. Many different explanations have been raised. Consequently, a wide range of conservative and surgical treatment options are available. Most of them address the intratendinous degenerative changes when present. Surgical measures include open excision of degenerative tendon. This means that the intratendinous changes are found responsible for the symptoms. But does the origin of the pain in these patients indeed rise from the Achilles tendon itself? It is known that the tendon itself is relatively aneuronal. It is also recognised that intratendinous degenerative changes often occur without symptoms.

It is hypothesised that the main cause of the pain in patients with symptomatic mid-portion Achilles tendinopathy does not arise from the tendon proper but is generated by its surrounding tissues. In this paper, a premise on the cause of pain based on existing knowledge and personal research is presented.

\section{Anatomy}

The Achilles tendon is the combination of tendons of soleus and gastrocnemius muscles, inserting approximately halfway the calcaneus. The gastrocnemius muscle crosses the knee, subtalar and ankle joints, originating from the posterior medial and lateral femoral condyles and inserting onto the calcaneus. The soleus muscle lies anterior to the 
gastrocnemius muscle and originates from the proximal tibia, fibula and interosseous membrane and crosses the ankle and subtalar joints. Distally, both the gastrocnemius and soleus muscles form an aponeurosis, from each of which a tendon originates. At about the level where the soleus contributes fibres to the Achilles tendon, rotation of the tendon begins and becomes more marked 2-7 $\mathrm{cm}$ proximal to the insertion onto the calcaneus. The gastrocnemius fibres rotate to lateral and the soleus fibres are positioned medial to the insertion [9, 21, 57]. Medial to the Achilles tendon the plantaris tendon is located, originating from the lateral femoral condyle and inserting onto the medial calcaneus. The Achilles tendon is involved in plantarflexion, whereas according to its anatomical course, the triarticular plantaris tendon also contributes to ankle inversion.

The Achilles and plantaris tendon are collectively surrounded by a paratenon, which lies on an inner layer of endotenon and exists on a layer of mesotenon and an outer layer of epitenon.

Tendon consists predominantly of extracellular tissue with low metabolic requirements and therefore appears white on macroscopic inspection. This relatively bradytrophic character enables the tendon to remain under tension for a long period, without the risk of necrosis or ischaemia. The Achilles tendon has 3 sources of vascular supply, which are (1) the perimyseal vessels at the musculotendinous junction; (2) periosteal vessels at the osteotendinous junction; and (3) vessels around the tendon within the paratenon, forming a capillary loop system. This last system is the main vascular supply for the Achilles tendon. The neural supply to the Achilles tendon and the surrounding paratenon is provided by nerves from the attaching muscles and by small fasciculi from cutaneous nerves, in particular the sural nerve [9, 71]. The number of nerves and nerve endings is relatively low, and the tendon proper is relatively aneuronal $[43,65]$.

\section{Aetiology}

A distinction is made between the aetiology of intratendinous degenerative changes and the aetiology of complaints in patients with mid-portion Achilles tendinopathy. Causes of intratendinous changes can be divided into extrinsic and intrinsic factors, but most commonly will be a combination of both. Malalignment of the foot, hyperpronation [63, 68], age [45] and chronic disease like diabetes mellitus, obesity and hypertension [28] have been described. Malalignment and hyperpronation impose excessive strain on the Achilles tendon. The ageing tendon loses its elastic properties causing the muscle to work more, resulting in a local rise in temperature with subsequent tendon changes [68].
Inappropriate physical training may also be an important issue [37, 46] causing degenerative Achilles tendon changes. Tendons transmit muscle forces to bone, allowing locomotion and enhancing joint stability. They respond to mechanical forces by changing their metabolism and their structural and mechanical properties. Appropriate training increases the diameter and tensile strength of tendons, with tendon fibroblasts increasing the production of collagen type I [42, 53, 72, 75]. Training also induces biochemical changes in tendons. Strenuous endurance training increases collagen turnover and decreases collagen maturation in tendons; excessive mechanical loading is considered a major concern. Repetitive strains below the failure threshold of the tendon cause tendon micro-injuries [38, 61]. Quality of foot gear and training surface influencing the alignment and statics of the ankle are also often mentioned as a cause of intratendinous pathology.

The aetiology of the pain in a patient with mid-portion Achilles tendinopathy has not yet been entirely clarified. Pain was believed to be caused by expansion of the Achilles tendon proper due to increased ground substance and an increased concentration of glucosaminoglycans (GAGs). A few years ago, the presence of neovascularisation around symptomatic tendons was raised as the cause of pain; now accompanying nerves with high concentrations of nociceptive substances [glutamate, substance $\mathrm{P}$, calcitonin gene-related peptide (CGRP)] are also supposed to play a role $[5,8]$.

\section{Clinical presentation}

Symptoms of a patient with mid-portion Achilles tendinopathy include painful swelling typically $2-7 \mathrm{~cm}$ proximal to the insertion and stiffness especially when getting up after a period of rest. Pain is the main symptom in Achilles tendinopathy that leads a patient to seek medical help. It is often most prominent $2-7 \mathrm{~cm}$ from the insertion onto the calcaneus on the medial side [67]. Tendinopathy and paratendinopathy often coexist [64]. Intratendinous changes most often remain asymptomatic [35]. In these cases, a painless swelling at $2-7 \mathrm{~cm}$ proximal to the insertion is the only finding [58]. In isolated paratendinopathy, there is local thickening of the paratenon. The area of swelling does not move with dorsiflexion and plantarflexion of the ankle, where it does in isolated tendinopathy [50, 69, 82]. Paratendinopathy can be acute or chronic. Acute isolated paratendinopathy manifests itself as painful peritendinous crepitus as the tendon glides within the inflamed covering. Areas of increased erythema, local heat and asymptomatic palpable tendon nodules or defects may also be present at clinical examination. In chronic paratendinopathy, 
exercise-induced pain is the main symptom while crepitation and swelling diminish.

\section{Histopathology}

\section{Normal situation}

Morphologically, healthy tendon is a complex composite material consisting of collagen fibrils embedded in a matrix of proteoglycans, with a relatively small number of cells. Between the parallel collagen bundles, fibroblasts are arranged, which are the predominant cells within tendons [10]. The matrix has tight bundles of long strands of type I collagen, which give the tendon its inherent strength. Between the collagen is the ground substance, made up of mainly small proteoglycans and glycosaminoglycan (GAG) chains. In normal tendon, there is minimal ground substance [14].

The paratenon consists of straight bundles of type I and type III collagen fibrils with straight microfibrillar arrangement and variable diameter [23, 41]. This peritendinous tissue is lined on its inner surface by synovial cells $[31,82]$ and acts as an elastic sleeve permitting the movement of tendon against the surrounding tissues [34]. The paratenon serves to carry blood vessels, lymphatics and nerves.

\section{Pathological situation}

In contrast to the white appearance of healthy tendon, in tendinopathy they macroscopically appear grey or yellowbrown and amorphous. Microscopically, the tendon shows disrupted collagen, a decrease in the amount of type I collagen and an increase in the amount of the weak type III collagen that is produced in response to injury and is less able to bundle. The classical hierarchical structure is lost, and there is increased ground substance with a high concentration of GAGs, more prominent and numerous tenocytes without their normal fine spindle shape and more rounded nuclei $[14,24]$. Some areas of tendinopathy become acellular [36] or have decreased cell numbers and function $[14,33]$.

In the peritendinous tissue in the chronic phase of Achilles tendinopathy, 2 types of cells have been identified: fibroblasts and myofibroblasts [41]. During biological processes that include extensive tissue remodelling, fibroblasts may acquire morphological and biochemical features of contractile cells, which have been named myofibroblasts [20]. The myofibroblasts have stress fibres composed of $\alpha$-smooth muscle actin in their cytoplasm and thus are capable of creating forces required for wound contraction [20]. In chronic Achilles tendinopathy, these cells are especially well established at the sites of scar formation, and it is estimated that about $20 \%$ of peritendinous cells are myofibroblasts [41]. The myofibroblasts synthesise abundant amounts of collagen and are believed to be responsible for the formation of permanent scarring and the shrinkage of peritendinous tissue around the tendon [30, 41]. They can induce and maintain a prolonged contracted state in the peritendinous adhesions around the tendon and thus influence the development of a contracture [30, 41]. This, in turn, may lead to the constriction of vascular channels and to impaired circulation and further contribute to the pathogenesis of Achilles tendinopathy. The proliferating connective tissue around the Achilles tendon causes increased intratendinous tension and pressure resulting in increased friction between the tendon, paratenon, crural fascia and the skin [30].

Vascularity seems increased in tendinopathy, as neovascularisation with thick walls, a tortuous appearance and small lumen ventral from the Achilles tendon and in the paratenon is found in 50-88\% of symptomatic tendons but not in pain-free tendons [18, 59, 60, 80, 83].

The healthy Achilles tendon proper is superficially innervated by the paratenon, but does not have a rich nervous supply itself [8]. It is normally aneuronal; conversely, chronic painful tendons have been shown to exhibit new ingrowth of nerve fibres accompanying the peritendinous neovascularisation from the paratenon into the tendon proper [43, 65]. Sensory nerve ingrowth has been observed as a reaction to repetitive loading [52] and also as a response to injury $[2,4]$. With this nerve ingrowth, levels of glutamate, calcitonin gene-related peptide (CGRP) and substance $\mathrm{P}$ rise $[4,8,43,65]$. These substances are all linked with increased nociception. Substance $\mathrm{P}$ is also associated with vasodilation and stimulates the proliferation of fibroblasts [70], possibly causing some of the morphologic changes in Achilles tendinopathy.

\section{Cause of pain}

Several factors play a role in the cause of pain in a patient with Achilles tendinopathy.

The process starts with localised tendon micro-injury and degeneration, which are caused by ageing and repetitive strain below the failure threshold of the tendon. The most hypovascular region is in the mid-portion area (2-7 cm from the insertion), where the tendon makes a marked twist. This is the location where the degeneration and micro-injury most often occur. Blood flow further declines with ageing and mechanical loading. When the demands of the tendon are higher than can be managed, micro-injuries develop [1]. The body reacts with a repair process, which is adequate in most cases, but inadequate in 
patients developing tendinopathy. This inadequate repair causes a repetitive cycle of inadequate collagen and matrix production, tenocyte disruption, a further decrease in collagen and matrix and an increased vulnerability to further micro-injuries. Due to the lack of blood vessels within the tendon, instead of a chemical, a neurogenic inflammatory process is activated to repair these microruptures. This neurogenic inflammation occurs in the tissue surrounding the Achilles tendon. Matrix metalloproteinases (MMPs) responsible for the degradation of extracellular matrix, cytokines [vascular endothelial growth factor (VEGF), epidermal growth factor (EGF) and platelet-derived growth factor (PDGF)] are overexpressed. VEGF promotes angiogenesis, upregulates the expression of MMPs and downregulates tissue inhibitors of metalloproteinases (TIMP-3), altering the properties of tendon. Invasion of vessels derived from the paratenon into a normally hypovascular intratendinous region weakens the normal tendon structure. When the repair of tendon is inadequate, e.g. due to submission to further loads without adequate recovery time or a declined blood flow due to ageing, the healing process fails and the pathogenic cascade leading to symptomatic tendinopathy occurs. The transition to symptomatic tendinopathy is marked by nerve proliferation accompanying the neovessels. Vascular ingrowth to repair the defect arises from the paratenon. These blood vessels are accompanied by sensory neonerves [11, 22] (Fig. 1), causing an increase in pain signalling by producing nociceptive substances [glutamate, substance $\mathrm{P}$, calcitonin gene-related peptide (CGRP)] past the critical threshold [5, 8]. Neovascularisation has indeed been found to correlate with the location of pain in patients with symptomatic tendinopathy [19]. The upregulated nociceptive substances further damage the tendon by inducing vasodilation, tendon cell apoptosis and the vicious circle of neurogenic inflammation [1, 5, 8, 22, 54].

Myofibroblasts proliferate and are transported by the peritendinous blood vessels and neovascularisation into the peritendineum and the tendon proper. Myofibroblasts not only synthesise abundant amounts of collagen to repair the tendon proper but also cause the formation of scar tissue around the tendon and consequently adhesions of the paratenon onto the Achilles tendon at the location of the neurovascular ingrowth. Scarring in turn may lead to the constriction of vascular channels and to impaired circulation and further contribute to the pathogenesis of Achilles tendinopathy, meaning that there is no further action towards repair.

Vasoconstriction and scarring with mechanical constriction will lead to the obliteration of neovessels. In $20-50 \%$ of long-lasting tendinopathy patients, no neovascularisation is found $[18,59,60,80,83]$. Nerves, however, will survive (Fig. 2), secreting glutamate and substance P causing pain on activity as described earlier.

Reduction in blood flow may also be explained by the fact that pathological tendons also exhibit a decreased occurrence of sympathetic nerve fibres. This reduction in vasoregulatory noradrenalin causes vasoconstriction [3].

It has been described that the location of the pain in patients with Achilles tendinopathy is most often located on the medial side [67, 69]. During Achilles tendoscopy in patients with Achilles tendinopathy, it has been observed that at the level of complaints the plantaris tendon is affixed onto the Achilles tendon on the medial side [69] (Fig. 3). Some authors describe a higher medial stress onto the Achilles tendon due to hyperpronation. This is supported by the finding that most ultrasonographic mid-portion disorders $(91 \%)$ are found in the posteromedial segment of the tendon [26,79].

In patients with a painful nodular thickening in the Achilles tendon, the pain is often most prominent on the medial side of the mid-portion Achilles tendon. At this level, the plantaris tendon runs closely with and parallel to the Achilles tendon.

The plantaris tendon originally is a knee and ankle flexor. In primates, it attaches to the plantar aspect of the proximal interphalangeal joints of the toes in primates, explaining its functionality for grasping with their feet.

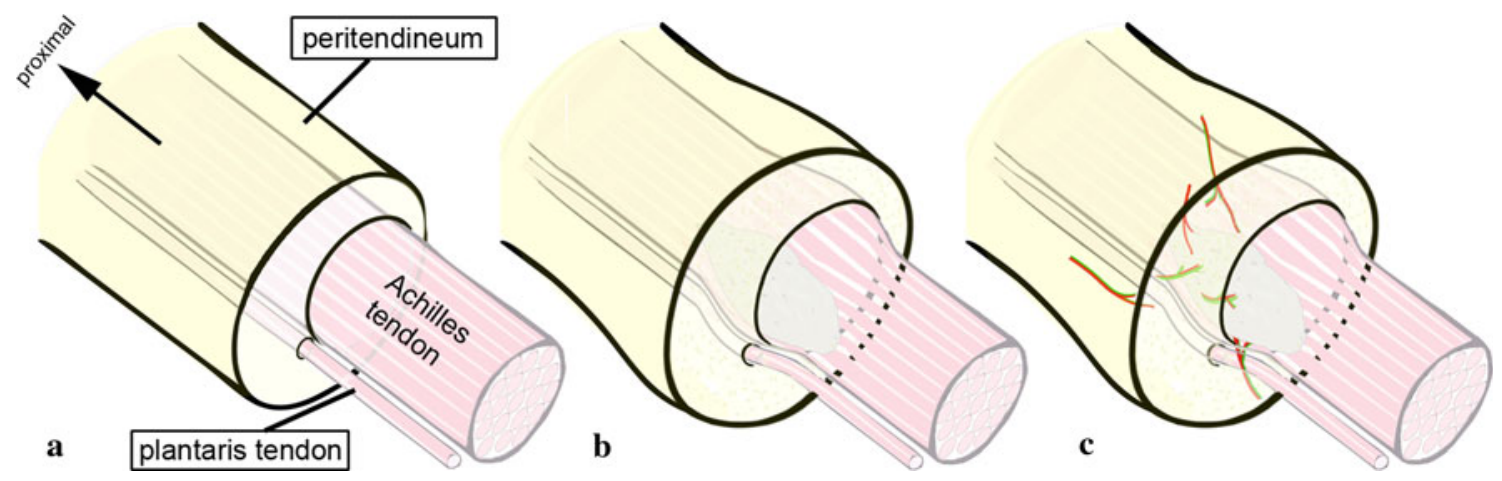

Fig. 1 a Schematic depiction of normal tendon. b Pathological tendon proper. c Vasculoneuronal ingrowth from the paratenon into the tendon proper 
Fig. 2 a Adhesion of the paratenon onto the Achilles tendon due to myofibroblast proliferation and consequently formation of scar tissue. b Continuing ingrowth of vessels and nerves and augmented adhesion. c Obliteration of neovessels due to constriction. d The painful end situation in which neovascularisation has been mostly obliterated but nerve endings persist

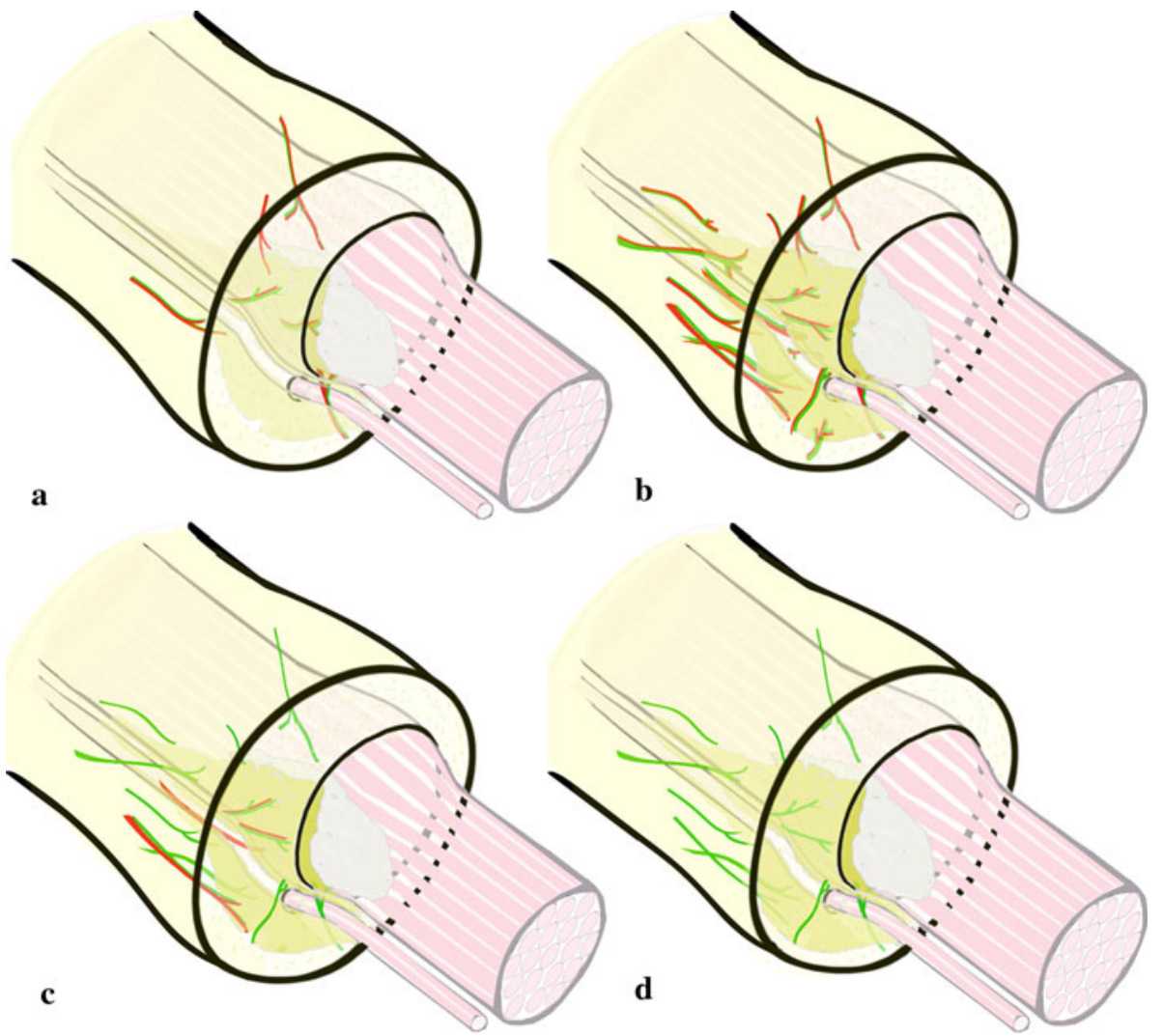

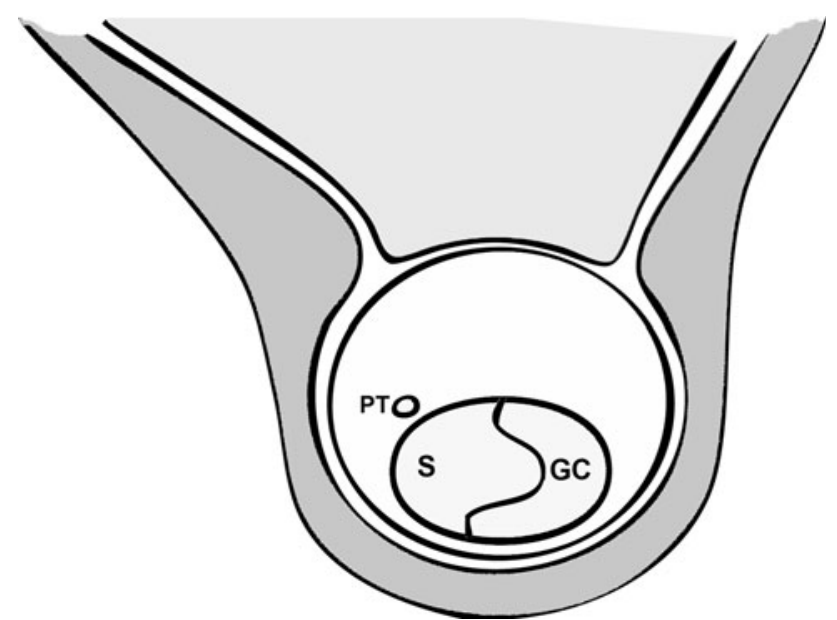

Fig. 3 The most common position $(52 \%)$ of the gastrocnemiussoleus complex at the mid-portion of the Achilles tendon [15]. (PT $=$ plantaris tendon, $\mathrm{S}=$ soleus, $\mathrm{GC}=$ gastrocnemius)

Darwinists suggest that through evolution in humans, the plantaris tendon is rudimental since human beings do not grasp with feet nor swing from trees any longer. Absence in $7-20 \%$ human lower limbs has been reported $[16,17,25$, $55,66]$.

In humans, the plantaris muscle is triangularly shaped and lies posterior to the knee joint, originating from the inferior part of the lateral supracondylar line of the femur. Its tendon travels inferomedially, posterior to the soleus muscle and anterior to the medial gastrocnemius muscle. The tendon crosses the calf relatively proximal, running medial from and parallel with the Achilles tendon from the mid-portion of the calf, in the majority of cases ultimately inserting medially onto the calcaneus $[17,27]$. The plantaris muscle-tendon complex nowadays is a weak ankle and knee flexor and ankle inverter.

The medial portion of the Achilles tendon consists solely of the soleus tendon since at about the level where the soleus contributes fibres to the Achilles tendon $(3-11 \mathrm{~cm})$, rotation of the tendon begins and becomes more marked in the distal 5-6 cm. Gastrocnemius fibres are therefore positioned lateral and the soleus fibres on the medial side of the insertion (Fig. 3). The soleus is biarticular (ankle and subtalar joints). The plantaris tendon runs anteromedial to it. It is believed that in a healthy situation, the plantaris tendon can move freely in relation to the Achilles tendon. Adhesions between plantaris and Achilles tendon can be the result of an inflammatory response of the paratenon, which is located around the Achilles and plantaris tendons.

The plantaris muscle-tendon complex not only causes flexion but also inversion, whereas the triceps surae is a flexor only. Adhesions between both tendons obstruct the opposite forces of these two bi and triarticular muscle 
Fig. 4 Endoscopic image of a patient with medial pain of his right Achilles tendon due to midportion Achilles tendinopathy. On Achilles tendoscopy, the paratenon is released from the Achilles tendon and in this image the plantaris tendon is identified. a The plantaris tendon is attached to the Achilles tendon. $\mathbf{b}$ With a trocar (in this case), the plantaris tendon is released from the Achilles tendon

Fig. 5 The rationale of Achilles tendoscopy. a With a blunt trocar, the paratenon is released from the Achilles tendon, b thereby the nerves are destructed. c The plantaris tendon is cut at the level of complaints. d In the postoperative weeks, remnants of nerves obliterate and the proximal end of the plantaris tendon retracts
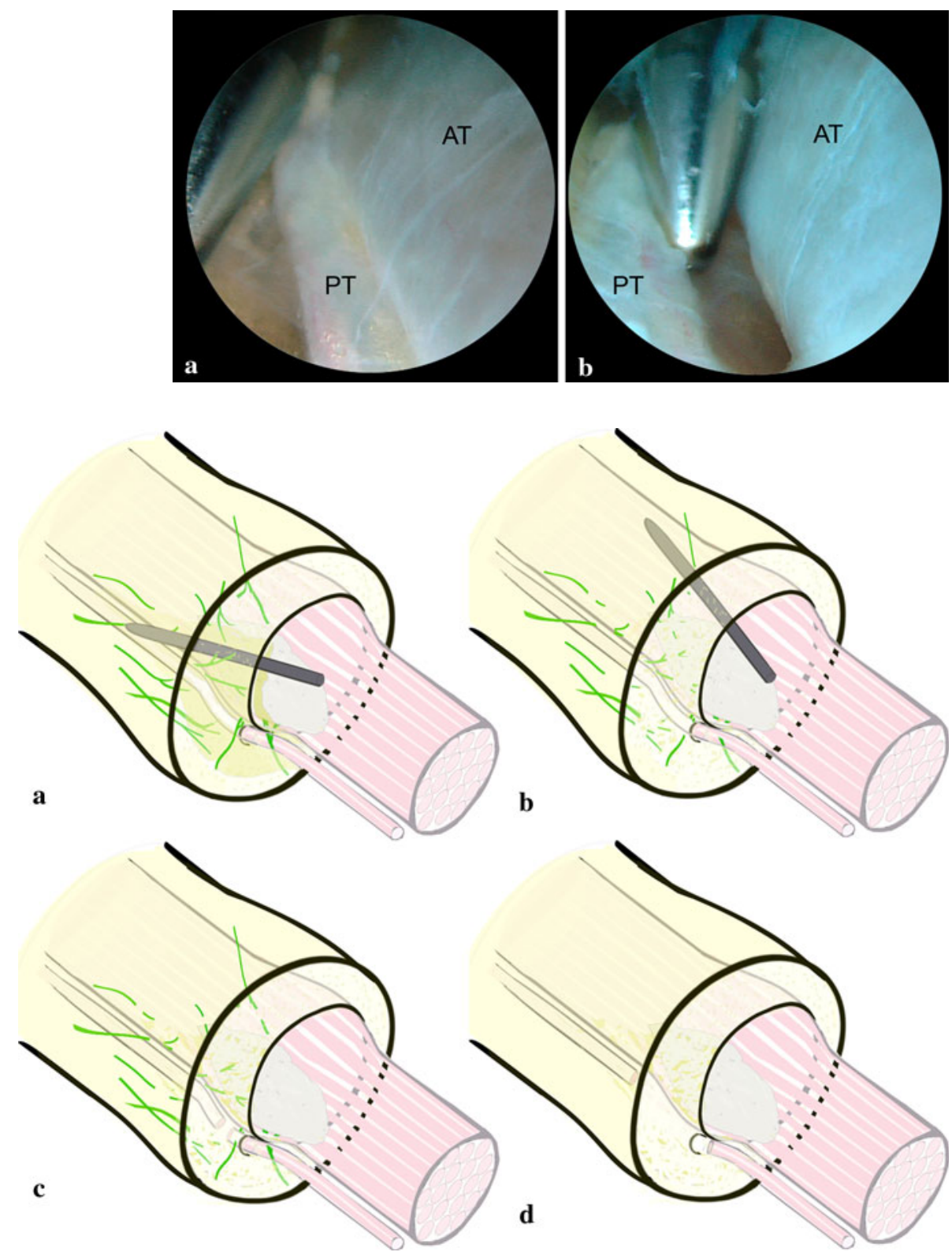

groups. Although the movement between the two will be limited, traction onto the surrounding paratenon will take place with every step with a mean of 5,000-12,500 steps/ day in people with a low active to active lifestyle [76, 77]. Chronic painful tendons have been shown to exhibit new ingrowth of sensory nerve fibres from the paratenon [43, 65]. Repetitive traction onto this richly innervated area might contribute to the medially located pain and stiffness during and after walking.

\section{Surgical treatment}

Most surgical procedures aim at debridement or tenotomy of the tendon itself. In all these procedures, the paratenon is incised, released or removed as well. In open surgical debridement of the tendon proper, the paratenon has to be opened [32, 40, 47, 62], and during minimally invasive tenotomy, the paratenon is also addressed. It is therefore uncertain which part of the procedure is responsible for a possible favourable outcome of such an approach. Paratendinopathy and tendinopathy often coexist. In some procedures, only peritendinous structures are addressed, such as in open or minimally invasive paratenectomy [44, 56] and Achilles tendoscopy where the paratenon is released and the plantaris tendon cut to relieve symptoms (Fig. 4) [51, 69]. These procedures render good results not in all but in $75-100 \%$ of patients. After treatment, most often functional and recovery time, although not often described, is 6 weeks to 6 months $[44,51,69,74]$. With 
surgery of the tendon proper, including minimally invasive tenotomy, the tendon is temporarily weakened. Recovery time until sport resumption therefore can be extensive and takes 3-18 months [12, 73, 81].

How can the favourable results of addressing the paratenon only in patients with symptomatic Achilles tendinopathy be explained? Pain relief could be explained by the destruction of the sensory nerves running from the paratenon into the Achilles tendon proper in these chronic patients: denervation of the Achilles tendon by releasing the paratenon may be the most important part of all these procedures (Fig. 5).

Positive results obtained from the more invasive conservative treatments may also be contributable to the destruction of nerve fibres. For example, sclerosing injections with polidocanol and high-volume image-guided injections (HVIGI) aim at obliterating neovessels and the accompanying nerve fibres $[6,13,29]$.

If pain can be relieved with denervation, extensive surgery of the tendon proper becomes redundant.

\section{Conclusion}

The goal of treatment of patients with chronic complaints of mid-portion Achilles tendinopathy is to relieve pain. Many surgical procedures focus on the debridement of alterations in the tendon proper. Since up to $34 \%$ of asymptomatic tendons show histopathological changes, it is now believed that the tendon proper is not the cause of pain in the majority of patients with symptomatic midportion Achilles tendinopathy. Chronic painful tendons show ingrowth of sensory and sympathetic nerves from the paratenon with the release of nociceptive substances. Denervating the Achilles tendon by release of the paratenon is sufficient to cause pain relief in the majority of patients. This type of treatment has the additional advantage that it is associated with a shorter recovery time when compared with treatment options that address the tendon itself.

Open Access This article is distributed under the terms of the Creative Commons Attribution Noncommercial License which permits any noncommercial use, distribution, and reproduction in any medium, provided the original author(s) and source are credited.

\section{References}

1. Abate M, Gravare SK, Siljeholm C, Di IA, De AD, Salini V, Werner S, Paganelli R (2009) Pathogenesis of tendinopathies: inflammation or degeneration? Arthritis Res Ther 11:235

2. Ackermann PW, Ahmed M, Kreicbergs A (2002) Early nerve regeneration after achilles tendon rupture-a prerequisite for healing? A study in the rat. J Orthop Res 20:849-856
3. Ackermann PW, Li J, Finn A, Ahmed M, Kreicbergs A (2001) Autonomic innervation of tendons, ligaments and joint capsules. A morphologic and quantitative study in the rat. J Orthop Res 19:372-378

4. Ackermann PW, Li J, Lundeberg T, Kreicbergs A (2003) Neuronal plasticity in relation to nociception and healing of rat achilles tendon. J Orthop Res 21:432-441

5. Alfredson H, Forsgren S, Thorsen K, Fahlstrom M, Johansson H, Lorentzon R (2001) Glutamate NMDAR1 receptors localised to nerves in human Achilles tendons. Implications for treatment? Knee Surg Sports Traumatol Arthrosc 9:123-126

6. Alfredson H, Ohberg L (2005) Sclerosing injections to areas of neo-vascularisation reduce pain in chronic Achilles tendinopathy: a double-blind randomised controlled trial. Knee Surg Sports Traumatol Arthrosc 13:338-344

7. Ames PR, Longo UG, Denaro V, Maffulli N (2008) Achilles tendon problems: not just an orthopaedic issue. Disabil Rehabil 30:1646-1650

8. Andersson G, Danielson P, Alfredson H, Forsgren S (2007) Nerve-related characteristics of ventral paratendinous tissue in chronic Achilles tendinosis. Knee Surg Sports Traumatol Arthrosc 15:1272-1279

9. Andres KH, von Düring M, Schmidt RF (1985) Sensory innervation of the Achilles tendon by group III and IV afferent fibers. Anat Embryol (Berl) 172:145-156

10. Beason DP, Soslowsky LJ, Karthikey T, Huard J (2009) Muscle, tendon, and ligament. In: Fischgrund JS (ed) American Academy of Orthopaedic Surgeons Orthopaedic Knowledge Update 9. Bayer Healthcare, Boston, pp 35-48

11. Bjur D, Alfredson H, Forsgren S (2005) The innervation pattern of the human Achilles tendon: studies of the normal and tendinosis tendon with markers for general and sensory innervation. Cell Tissue Res 320:201-206

12. Bohu Y, Lefevre N, Bauer T, Laffenetre O, Herman S, Thaunat M, Cucurulo T, Franceschi JP, Cermolacce C, Rolland E (2009) Surgical treatment of Achilles tendinopathies in athletes. Multicenter retrospective series of open surgery and endoscopic techniques. Orthop Traumatol Surg Res 95:S72-S77

13. Chan O, O'Dowd D, Padhiar N, Morrissey D, King J, Jalan R, Maffulli N, Crisp T (2008) High volume image guided injections in chronic Achilles tendinopathy. Disabil Rehabil 30:1697-1708

14. Cook JL, Khan KM, Purdam C (2002) Achilles tendinopathy. Man Ther 7:121-130

15. Cummins EJ, Anson JB, Carr WB (1946) The structure of the calcaneal tendon of Achilles in relation to orthopedic surgery with additional observations on the plantaris muscle. Surg Gynecol Obstet 83:107-110

16. Danforth CH (1923) The heredity of unilateral variations in man. Genetics 9:199-210

17. Daseler EH (1943) The plantaris muscle: an anatomical study of 750 specimens. J Bone Joint Surg 25:822-827

18. de Vos RJ, Weir A, Cobben LP, Tol JL (2007) The value of power Doppler ultrasonography in Achilles tendinopathy: a prospective study. Am J Sports Med 35:1696-1701

19. Divani K, Chan O, Padhiar N, Twycross-Lewis R, Maffulli N, Crisp T, Morrissey D (2010) Site of maximum neovascularisation correlates with the site of pain in recalcitrant mid-tendon Achilles tendinopathy. Man Ther 15:463-468

20. Ehrlich HP, Desmouliere A, Diegelmann RF, Cohen IK, Compton CC, Garner WL, Kapanci Y, Gabbiani G (1994) Morphological and immunochemical differences between keloid and hypertrophic scar. Am J Pathol 145:105-113

21. Evans NA, Stanish WD (2000) The basic science of tendon injuries. Curr Orthop 14:403-412

22. Forsgren S, Danielson P, Alfredson H (2005) Vascular NK-1 receptor occurrence in normal and chronic painful Achilles and 
patellar tendons: studies on chemically unfixed as well as fixed specimens. Regul Pept 126:173-181

23. Franchi M, Quaranta M, De Pasquale, V, Macciocca M, Orsini E, Trire A, Ottani V, Ruggeri A (2007) Tendon crimps and peritendinous tissues responding to tensional forces. Eur J Histochem 51 Suppl 1:9-14

24. Fredberg U, Stengaard-Pedersen K (2008) Chronic tendinopathy tissue pathology, pain mechanisms, and etiology with a special focus on inflammation. Scand J Med Sci Sports 18:3-15

25. Freeman AJ, Jacobson NA, Fogg QA (2008) Anatomical variations of the plantaris muscle and a potential role in patellofemoral pain syndrome. Clin Anat 21:178-181

26. Gibbon WW, Cooper JR, Radcliffe GS (2000) Distribution of sonographically detected tendon abnormalities in patients with a clinical diagnosis of chronic achilles tendinosis. J Clin Ultrasound 28:61-66

27. Harvey FJ, Chu G, Harvey PM (1983) Surgical availability of the plantaris tendon. J Hand Surg [Am] 8:243-247

28. Holmes GB, Lin J (2006) Etiologic factors associated with symptomatic achilles tendinopathy. Foot Ankle Int 27:952-959

29. Humphrey J, Chan O, Crisp T, Padhiar N, Morrissey D, Twycross-Lewis R, King J, Maffulli N (2010) The short-term effects of high volume image guided injections in resistant non-insertional Achilles tendinopathy. J Sci Med Sport 13:295-298

30. Jarvinen M, Jozsa L, Kannus P, Jarvinen TL, Kvist M, Leadbetter W (1997) Histopathological findings in chronic tendon disorders. Scand J Med Sci Sports 7:86-95

31. Jozsa L, Balint J (1978) Pathology of the spontaneous tendon ruptures (author's transl). Magy Traumatol Orthop Helyreallito Seb 21:176-193

32. Jozsa L, Kannus P (1997) Human tendons: anatomy, physiology, and pathology. Hum Kinet 1:204-206

33. Jozsa L, Reffy A, Kannus P, Demel S, Elek E (1990) Pathological alterations in human tendons. Arch Orthop Trauma Surg 110:15-21

34. Kannus P (2000) Structure of the tendon connective tissue. Scand J Med Sci Sports 10:312-320

35. Kannus P, Jozsa L (1991) Histopathological changes preceding spontaneous rupture of a tendon. A controlled study of 891 patients. J Bone Joint Surg Am 73:1507-1525

36. Khan KM, Bonar F, Desmond PM, Cook JL, Young DA, Visentini PJ, Fehrmann MW, Kiss ZS, O'Brien PA, Harcourt PR, Dowling RJ, O'Sullivan RM, Crichton KJ, Tress BM, Wark JD (1996) Patellar tendinosis (jumper's knee): findings at histopathologic examination, US, and MR imaging. Victorian Institute of Sport Tendon Study Group. Radiology 200: 821-827

37. Khan KM, Maffulli N (1998) Tendinopathy: an Achilles' heel for athletes and clinicians. Clin J Sport Med 8:151-154

38. Kjaer M (2004) Role of extracellular matrix in adaptation of tendon and skeletal muscle to mechanical loading. Physiol Rev 84:649-698

39. Kujala UM, Sarna S, Kaprio J (2005) Cumulative incidence of achilles tendon rupture and tendinopathy in male former elite athletes. Clin J Sport Med 15:133-135

40. Kvist H, Kvist M (1980) The operative treatment of chronic calcaneal paratenonitis. J Bone Joint Surg Br 62:353-357

41. Kvist M, Jozsa L, Jarvinen M, Kvist H (1985) Fine structural alterations in chronic Achilles paratenonitis in athletes. Pathol Res Pract 180:416-423

42. Langberg H, Rosendal L, Kjaer M (2001) Training-induced changes in peritendinous type I collagen turnover determined by microdialysis in humans. J Physiol 534:297-302

43. Lian O, Dahl J, Ackermann PW, Frihagen F, Engebretsen L, Bahr $\mathrm{R}$ (2006) Pronociceptive and antinociceptive neuromediators in patellar tendinopathy. Am J Sports Med 34:1801-1808
44. Longo UG, Ramamurthy C, Denaro V, Maffulli N (2008) Minimally invasive stripping for chronic Achilles tendinopathy. Disabil Rehabil 30:1709-1713

45. Macaluso A, De VG (2004) Muscle strength, power and adaptations to resistance training in older people. Eur J Appl Physiol 91:450-472

46. Maffulli N (1998) Current concepts in the management of subcutaneous tears of the Achilles tendon. Bull Hosp Jt Dis $57: 152-158$

47. Maffulli N, Binfield PM, Moore D, King JB (1999) Surgical decompression of chronic central core lesions of the Achilles tendon. Am J Sports Med 27:747-752

48. Maffulli N, Khan KM, Puddu G (1998) Overuse tendon conditions: time to change a confusing terminology. Arthroscopy 14:840-843

49. Maffulli N, Sharma P, Luscombe KL (2004) Achilles tendinopathy: aetiology and management. J R Soc Med 97:472-476

50. Maffulli N, Walley G, Sayana MK, Longo UG, Denaro V (2008) Eccentric calf muscle training in athletic patients with Achilles tendinopathy. Disabil Rehabil 30:1677-1684

51. Maquirriain J, Ayerza M, Costa-Paz M, Muscolo DL (2002) Endoscopic surgery in chronic achilles tendinopathies: a preliminary report. Arthroscopy 18:298-303

52. Messner K, Wei Y, Andersson B, Gillquist J, Rasanen T (1999) Rat model of Achilles tendon disorder. A pilot study. Cells Tissues Organs 165:30-39

53. Michna H, Hartmann G (1989) Adaptation of tendon collagen to exercise. Int Orthop 13:161-165

54. Molloy TJ, Kemp MW, Wang Y, Murrell GA (2006) Microarray analysis of the tendinopathic rat supraspinatus tendon: glutamate signaling and its potential role in tendon degeneration. J Appl Physiol 101:1702-1709

55. Moss ALH (1988) Is there an association between an absence of palmaris longus tendon and an absence of plantaris tendon? Eur $\mathbf{J}$ Plast Surg 11:32-34

56. Nelen G, Martens M, Burssens A (1989) Surgical treatment of chronic Achilles tendinitis. Am J Sports Med 17:754-759

57. O'Brien M (2005) The anatomy of the Achilles tendon. Foot Ankle Clin 10:225-238

58. Pearce C, Donley B, Calder J (2010) Achilles tendinopathy: nonoperative treatment. In: Calder J, Karlsson J, Maffulli N, Thermann H, van Dijk CN (eds) Achilles tendinopathy: current concepts, 1st edn. DJO Publications, London, pp 79-87

59. Peers KH, Brys PP, Lysens RJ (2003) Correlation between power Doppler ultrasonography and clinical severity in Achilles tendinopathy. Int Orthop 27:180-183

60. Reiter M, Ulreich N, Dirisamer A, Tscholakoff D, Bucek RA (2004) Extended field-of-view sonography in Achilles tendon disease: a comparison with MR imaging. Rofo 176:704-708

61. Riley G (2008) Tendinopathy_from basic science to treatment. Nat Clin Pract Rheumatol 4:82-89

62. Rolf C, Movin T (1997) Etiology, histopathology, and outcome of surgery in achillodynia. Foot Ankle Int 18:565-569

63. Ryan M, Grau S, Krauss I, Maiwald C, Taunton J, Horstmann T (2009) Kinematic analysis of runners with achilles mid-portion tendinopathy. Foot Ankle Int 30:1190-1195

64. Saxena A (1995) Surgery for chronic Achilles tendon problems. J Foot Ankle Surg 34:294-300

65. Schubert TE, Weidler C, Lerch K, Hofstadter F, Straub RH (2005) Achilles tendinosis is associated with sprouting of substance P positive nerve fibres. Ann Rheum Dis 64:1083-1086

66. Schwalbe G, Pfitzner W (1894) Varietäten-Statistik und Anthropologie. Deutsche Med Wchnschr XXV:459

67. Segesser B, Goesele A, Renggli P (1995) The Achilles tendon in sports. Orthopade 24:252-267

68. Sharma P, Maffulli N (2005) Tendon injury and tendinopathy: healing and repair. J Bone Joint Surg Am 87:187-202 
69. Steenstra F, van Dijk CN (2006) Achilles tendoscopy. Foot Ankle Clin 11:429-438

70. Steyaert AE, Burssens PJ, Vercruysse CW, Vanderstraeten GG, Verbeeck RM (2006) The effects of substance P on the biomechanic properties of ruptured rat Achilles' tendon. Arch Phys Med Rehabil 87:254-258

71. Stilwell DL Jr (1957) The innervation of tendons and aponeuroses. Am J Anat 100:289-317

72. Suominen H, Kiiskinen A, Heikkinen E (1980) Effects of physical training on metabolism of connective tissues in young mice. Acta Physiol Scand 108:17-22

73. Testa V, Capasso G, Benazzo F, Maffulli N (2002) Management of Achilles tendinopathy by ultrasound-guided percutaneous tenotomy. Med Sci Sports Exerc 34:573-580

74. Thermann H, Benetos IS, Panelli C, Gavriilidis I, Feil S (2009) Endoscopic treatment of chronic mid-portion Achilles tendinopathy: novel technique with short-term results. Knee Surg Sports Traumatol Arthrosc 17:1264-1269

75. Tipton CM, Matthes RD, Maynard JA, Carey RA (1975) The influence of physical activity on ligaments and tendons. Med Sci Sports 7:165-175

76. Tudor-Locke C, Bassett DR Jr (2004) How many steps/day are enough? Preliminary pedometer indices for public health. Sports Med 34:1-8
77. Tudor-Locke C, Hatano Y, Pangrazi RP, Kang M (2008) Revisiting "how many steps are enough?". Med Sci Sports Exerc 40:S537-S543

78. van Dijk CN, van Sterkenburg MN, Wiegerinck JI, Karlsson J, Maffulli N (2011) Terminology for Achilles tendon related disorders. Knee Surg Sports Traumatol Arthrosc 19:835-841

79. van Schie HT, de Vos RJ, de JS, Bakker EM, Heijboer MP, Verhaar JA, Tol JL, Weinans H (2010) Ultrasonographic tissue characterisation of human Achilles tendons: quantification of tendon structure through a novel non-invasive approach. Br J Sports Med 44:1153-1159

80. van Sterkenburg MN, de Jonge MC, Sierevelt IN, van Dijk CN (2010) Less promising results with sclerosing ethoxysclerol injections for midportion achilles tendinopathy: a retrospective study. Am J Sports Med 38:2226-2232

81. Vega J, Cabestany JM, Golano P, Perez-Carro L (2008) Endoscopic treatment for chronic Achilles tendinopathy. Foot Ankle Surg 14:204-210

82. Williams JG (1986) Achilles tendon lesions in sport. Sports Med 3:114-135

83. Zanetti M, Metzdorf A, Kundert HP, Zollinger H, Vienne P, Seifert B, Hodler J (2003) Achilles tendons: clinical relevance of neovascularization diagnosed with power Doppler US. Radiology 227:556-560 